\title{
Food Safety Practices among Postnatal Mothers in Western Ghana
}

\author{
Stephen T. Odonkor $\mathbb{D D}^{1}{ }^{1}$ Napoleon Kurantin, ${ }^{1}$ and Anthony M. Sallar ${ }^{2}$ \\ ${ }^{1}$ School of Public Service and Governance, Ghana Institute of Management and Public Administration, Accra, Ghana \\ ${ }^{2}$ School of Liberal \& Social Sciences, Ghana Institute of Management and Public Administration, Accra, Ghana \\ Correspondence should be addressed to Stephen T. Odonkor; stodonkor@gimpa.edu.gh
}

Received 20 May 2020; Revised 29 October 2020; Accepted 8 November 2020; Published 23 November 2020

Academic Editor: Alejandro Castillo

Copyright (c) 2020 Stephen T. Odonkor et al. This is an open access article distributed under the Creative Commons Attribution License, which permits unrestricted use, distribution, and reproduction in any medium, provided the original work is properly cited.

\begin{abstract}
Food safety has become a global issue due to the morbidity and mortality associated with it, particularly in developing countries. The objective of this community-based study is to examine food safety practices and its associated factors among postnatal mothers in the Western Region of Ghana. A cross-sectional survey study was conducted from August 12019 to January 31, 2020 from which data was obtained from the postnatal mothers $(N=300)$. The data was analysed using SPSS v.23. The findings suggest that majority (86\%) of the respondents exhibited good food handling practices. Also, $66.3 \%$ and $91.7 \%$ of the respondents exhibited good food preparation and proper storage practices, respectively. Results also revealed that the odds of performing good handling practice among respondents within the age group of 36-45 years were five times higher compared to those within the age group of $18-25$ years [OR $=4.92$ (95\% CI: $1.44-16.86), p=0.011]$. Moreover, respondents who had tertiary education qualifications were more likely to have proper food handling practices compared to those with primary education [OR $=0.27$ (95\% CI: 0.09-0.71), $p=0.009$ ]. These findings provide useful insights for policy directions. The government of Ghana and other stakeholders should develop a communication strategy to increase and sustain publicity and education on food safety particularly to postnatal mothers and the citizenry in general.
\end{abstract}

\section{Introduction}

In recent times, food safety has become an issue of global attention particularly due to its significant link to public health and the need to minimise foodborne diseases [1]. Moreover, food safety is critical in sustaining food security in every nation [2]. One major global concern about unsafe food is its high probability of causing diseases which are usually termed as foodborne diseases. Foodborne diseases are significant causes of deaths and a major hindrance to physical productivity and socioeconomic development worldwide (WHO, 2015). Though the full scale of the global estimates of foodborne diseases is uncertain, it is estimated that generally, the discovered 31 worldwide foodborne hazards caused about 600 million foodborne illnesses and 600,000 deaths in 2010 alone [3]. According to the World Health Organization, Africa and Asia are perceived to have the highest incidence of foodborne disease. There are over 250 foodborne diseases $[4,5]$. A study in Ghana using data from 2009 to 2013 revealed cholera as the predominant foodborne disease [5].
Unsafe food handling practices tend to increase the transmission of foodborne diseases [1]. A food handler is anyone who manipulates food or anything that has a high probability of coming into contact with food or foodstuffs [6]. Food handlers play a vital role in ensuring food safety and as a result, the global concern towards this issue significantly involves them as well [7]. About $10 \%$ to $20 \%$ of foodborne disease occurrences have been attributed to contamination by food handlers [8]. It is well recognized that food handlers in homes, who are usually mothers, are important last line of defence against foodborne disease outbreak. Thus, their relevance in ensuring food safety in homes cannot be underestimated ([1]; Rao et al., 2007; [9]). Other studies have further highlighted that over $50 \%$ of foodborne diseases come from domestic homes $[10,11]$, which is aggravated by lack of requisite food safety practices and knowledge [11, 12]. Hence, investigation of food safety practices among mothers is highly needed. For postnatal mothers, food safety practices are extremely relevant not only for their personal health but also for good child care. Children have an undeveloped 


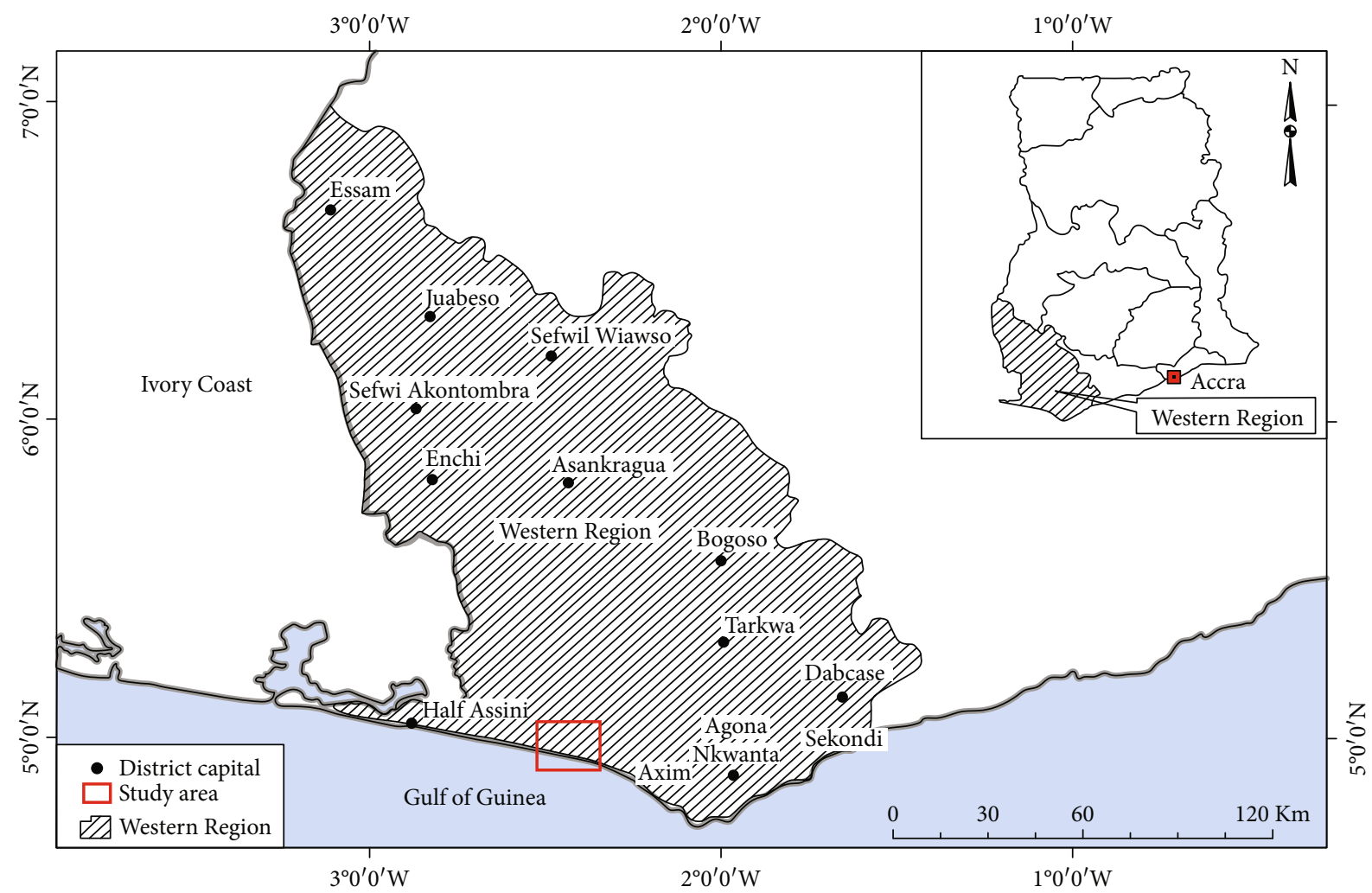

Figure 1: Map of the Western Region.

immune system and, as a result, are at higher risks of acquiring foodborne diseases than adults. Statistics show that out of the 2.2 million people who die annually due to foodborne diseases in developing countries, an estimated 1.9 million are children [12]. Additionally, $40 \%$ of foodborne disease burden in 2010 were among children under 5 years of age, globally (WHO, 2015).

There have been studies conducted to investigate food safety practices among street vendors and other institutional centres in Ghana [13-15], but in relation to mothers, such studies are almost elusive despite the reported significant contribution of mothers to the increasing rate of foodborne diseases. Thus, food safety practices and its associated factors among mother, including postnatal mothers, are poorly understood in Ghana. Investigating food safety practices among food handlers is very necessary for guiding policymakers to put up structures that will minimize the foodborne disease outbreak. In a recent study in Ethiopia, half of the participants had a good self-reported food safety practice, and the other half's level was poor [1]. In another study, mothers had good knowledge on personal hygiene and food poisoning, but their food handling practices were poor. These findings showed that good knowledge of food safety does not necessarily translate into good attitudes and practices. Knowledge, attitudes, and practices of food safety are important in preventing food poisoning [16]. Hence, the objective of this community-based study is to examine food safety practices and its associated factors among postnatal mothers in the Western Region of Ghana.

\section{Materials and Methods}

2.1. Study Site Description. The Western Region of Ghana is the home to Ghana's only twin city: Sekondi-Takoradi. The region can be found in the southern part of Ghana (Figure 1). It is sandwiched between Ivory Coast to the west and the central region to the east. The Western region of Ghana has a coast line as its south boundary. The region occupies a land size of 23,921 sq. $\mathrm{km}$. This accounts for about $10 \%$ of Ghana's total land area. The population of the region as of 2019 is estimated to be $2,165,241$ out of which females constitute 1,100,443 (GSS, 2020). There are 13 districts in the region, and the population density is $80.5 \mathrm{sq}$. km. Females have lower literacy rate $(47.9 \%)$ in the region as compared to males $(68.0 \%)$.

2.2. Research Design. The study employed a cross-sectional design. Self-administered questionnaires were used to obtain data on food safety practices and its associated factors among postnatal mothers in the Western Region of Ghana. The study was conducted from August 1, 2019 to January 31, 2020. Questionnaires were self-administered and took an average of 28 minutes to complete. The average margin of error is $95 \%$ confidence interval.

2.3. Sampling Technique. Data were obtained from a regionally representative survey of postnatal mothers $(N=300)$. The study utilized a stratified sampling technique. The region was demarcated into 3 zones: southern-western belt, middle 
belt, and northwestern belt. The study utilized a stratified sampling technique to obtain the required number of respondents from hospitals within the three (3) demarcated zones. Thus, in selecting the respondents, sampling proportionate to size was used to determine the number of postnatal mothers to be interviewed from each category of the zones. All postnatal mothers present in the demarcated zone were considered for the study.

2.4. Sample Size. The sample size for the study was determined using the Miller and Brower formula $(n=N / 1+$ $\left.N[\alpha)^{2}\right]$ ) for the sample size estimation [17]. The formula was thus employed to determine the sample taken from each hospital. In the formulae: $n=$ sample size, $N=$ total population, and $\alpha=$ margin of error, nonresponses and inappropriately filled questionnaires were accounted for by increasing the minimum sample size by $10 \%$. Thus, a total of 316 questionnaires were distributed for the study. However, 300 were completely filed and returned. This represents a $95 \%$ response rate.

2.5. Data Collection Instrument. A standardized questionnaire was used to obtain the data. Field inspection of the questionnaire data was carried out days after the interview were conducted, and any errors were immediately verified and corrected. The survey instrument comprised of 21 questions in four (4) thematic areas, namely, demographic characteristics, food handling practices among postnatal mothers, food storage practices among postnatal mothers, and food preparation practices among postnatal mothers. The questionnaire was designed and administered in the English language. It took approximately 25-30 minutes to complete the instrument. Six experts in social sciences measurement and evaluation determined face validity of the instrument. The average overall face validity was equal to 95\%. The study used Cronbach's alpha test formula to test the reliability of the standard questionnaire. The test yielded a reliability coefficient of 0.8 . Cronbach's alpha test assesses the internal consistency of a set of scale of or items to ensure that they are all consistent in measuring the same attributes under study.

2.6. Ethical Considerations and Data Handling. Ethical clearance was obtained from the School of Public Service and Governance (SPSG) Ethics Review Committee of the Ghana Institute of Management and Public Administration. Prior to the data collection, respondents' written and verbal consent was sought. The data were entered into an excel spreadsheet and later exported to SPSS version 23 and coded for analysis. Descriptive statistics and inferential statistical methods were used to describe the variables of interest.

\section{Results and Discussion}

3.1. Results. Table 1 shows the demographic characteristics of the respondents. It can be seen from the table that more than half (59\%) of the respondents were within the 26-35 years age group. Majority of the respondents $(65.3 \%)$ had an average monthly income of GHC 600. Almost all of the respondents (96\%) were married whilst less than $1 \%$ of them were
TABle 1: Demographic characteristics of respondents.

\begin{tabular}{|c|c|c|}
\hline Variable & Frequency & Percentage \\
\hline \multicolumn{3}{|l|}{ Age group } \\
\hline $18-25$ years & 44 & 14.7 \\
\hline 26-35 years & 177 & 59.0 \\
\hline $36-45$ years & 71 & 23.7 \\
\hline Above 45 years & 8 & 2.6 \\
\hline \multicolumn{3}{|l|}{ Monthly income } \\
\hline$<$ Ghc500 & 83 & 27.7 \\
\hline Ghc600-1000 & 196 & 65.3 \\
\hline Ghc1001-1500 & 12 & 4.0 \\
\hline$>$ Ghc1500 & 9 & 3.0 \\
\hline \multicolumn{3}{|l|}{ Marital status } \\
\hline Married & 288 & 96.0 \\
\hline Single & 11 & 3.7 \\
\hline Divorced & 1 & 0.3 \\
\hline \multicolumn{3}{|l|}{ Religion } \\
\hline Christianity & 293 & 97.7 \\
\hline Islamic & 7 & 2.3 \\
\hline \multicolumn{3}{|l|}{ Type of delivery } \\
\hline Normal & 290 & 96.67 \\
\hline Caesarean & 10 & 3.33 \\
\hline \multicolumn{3}{|l|}{ Educational level } \\
\hline Primary & 264 & 88.0 \\
\hline Secondary & 16 & 5.3 \\
\hline Tertiary & 20 & 6.7 \\
\hline \multicolumn{3}{|l|}{ Number of children } \\
\hline One & 33 & 11.0 \\
\hline Two & 52 & 17.3 \\
\hline Three & 209 & 69.7 \\
\hline Four & 4 & 1.3 \\
\hline Five & 2 & 0.7 \\
\hline
\end{tabular}

divorced. Majority of the respondents (88\%) attained the primary level of education, and also $6.7 \%$ had completed tertiary education. Majority (69.7\%) of the respondents had given birth to three children.

Table 2 presents food handling practices among respondents. Almost all (99.3\%) of the respondents agreed that washing hands before handling food reduces the risk of food contamination. Majority (82.75) of the respondents also disagreed that it is necessary not to handle food during infectious disease of the skin. Moreover, $97.3 \%$ of the respondents agreed that there is a need to check for expiry dates especially on canned foods before consumption. Most of the respondents (84.3\%) agreed that using gloves while handling food reduces the risk of food contamination.

Table 3 shows the food preparation practices among the respondents. Almost all of the respondents, 99.3\%, agree that washing hands before handling food reduces the risk of food contamination. More than half of the respondents also agree that it is not necessary to handle food during infectious disease of the skin. Moreover, majority of the respondents 
TABLE 2: Food handling practices among the respondents.

\begin{tabular}{|c|c|c|c|}
\hline Variable & $\begin{array}{l}\text { Agree, } \\
\text { no. }(\%)\end{array}$ & $\begin{array}{c}\text { Disagree, } \\
\text { no. (\%) }\end{array}$ & $\begin{array}{c}\text { Do not know, } \\
\text { no. }(\%)\end{array}$ \\
\hline Washing hands before handling food reduces the risk of food contamination & $298(99.3)$ & $2(0.7)$ & $0(0)$ \\
\hline Using gloves while handling food reduces the risk of food contamination & $253(84.3)$ & $39(13.0)$ & $8(2.7)$ \\
\hline Improper cleaning and sanitization of utensils increases the risk of food contamination & $256(85.3)$ & $43(14.3)$ & $1(0.4)$ \\
\hline Reheating cooked foods contributes to food contamination & $37(12.3)$ & $258(86.0)$ & $5(1.7)$ \\
\hline Crosscontamination occurs when microorganisms are transferred by the food handler's hand & $290(96.7)$ & $8(2.6)$ & $2(0.7)$ \\
\hline It is necessary to handle food during infectious disease of the skin & $51(17.0)$ & $248(82.7)$ & $1(0.3)$ \\
\hline Need to check the expiry date of canned food & $292(97.3)$ & $6(2.0)$ & $2(0.7)$ \\
\hline Read the instruction for use and for preservation written on the pack & $293(97.7)$ & $6(2.0)$ & $1(0.3)$ \\
\hline Check if a canned food is dented before you buy & $286(95.3)$ & $11(3.7)$ & $3(1.0)$ \\
\hline
\end{tabular}

TABLE 3: Food preparation practices among the respondents.

\begin{tabular}{|c|c|c|c|c|c|}
\hline Variable & $\begin{array}{c}\text { Always, } \\
\text { no. (\%) }\end{array}$ & $\begin{array}{c}\text { Often, } \\
\text { no. (\%) }\end{array}$ & $\begin{array}{c}\text { Sometimes, } \\
\text { no. }(\%)\end{array}$ & $\begin{array}{l}\text { Rarely, } \\
\text { no. (\%) }\end{array}$ & $\begin{array}{l}\text { Never, } \\
\text { no. }(\%)\end{array}$ \\
\hline Cover dustbins where food is prepared & $292(97.3)$ & $3(1.0)$ & $4(1.3)$ & $1(0.4)$ & $0(0)$ \\
\hline Availability of potable water for cooking & $292(97.2)$ & $1(0.3)$ & $7(2.4)$ & $0(0)$ & $0(0)$ \\
\hline Use clean water to wash hands and plates & $296(98.7)$ & $2(0.7)$ & $1(0.3)$ & $1(0.3)$ & $0(0)$ \\
\hline Cover hair when preparing food & $277(92.3)$ & $6(2.0)$ & $11(3.7)$ & $6(2.0)$ & $0(0)$ \\
\hline Ensure that fingernails are kept short and clean when cooking & $49(16.3)$ & $7(2.3)$ & $241(80.4)$ & $3(1.0)$ & $0(0)$ \\
\hline Cover mouth with handkerchief when sneezing or yawning & $279(93.0)$ & $4(1.33)$ & $16(5.33)$ & $1(0.33)$ & $0(0)$ \\
\hline Cook when have foodborne or airborne disease & $77(25.7)$ & $9(3.0)$ & $21(7.0)$ & $13(4.3)$ & $180(60.0)$ \\
\hline Wash hands with soap and water after using the washroom & $274(91.3)$ & $8(2.70$ & $3(1.0)$ & $9(3.0)$ & $6(2.0)$ \\
\hline Wash hands with soap before cooking & $288(96.0)$ & $9(3.0)$ & $3(1.0)$ & $0(0)$ & $0(0)$ \\
\hline Clean foodstuffs before cooking them & $286(95.3)$ & $2(0.7)$ & $3(1.0)$ & $2(0.7)$ & $7(2.3)$ \\
\hline
\end{tabular}

$97.3 \%$ agree that there is a need to check for expiry dates especially on canned foods before consumption to help avoid foodborne disease. Most of the respondents, $84.3 \%$, agree to the fact that using gloves while handling food reduces the risk of food contamination.

Table 4 shows the food storage practices among the respondents. Almost everyone (96.3\%) purchases frozen meat at the end of their shopping trip. Also, a majority (95\%) of the respondents put food that will be consumed in 3-4 hours, on the table or the counter and reheat it before consumption. Almost all of the respondents (87.7\%) indicated that leftovers should not be kept in a fridge for more than 2 days.

Figure 2 shows the places the respondents shop for their food preparation. Almost all (90.3\%) of the respondents did their shopping at the market, while $8.7 \%$ shopped at the super market and only $1 \%$ at the special retail shop.

Figure 3 presents food handling, preparation, and storage practices among respondents. The findings suggest that majority ( $86 \%)$ of the respondents exhibited good food handling practices. It was revealed that $66.3 \%$ of the respondents had good food preparation practices. The findings also suggest that majority $(91.7 \%)$ of the respondents were storing food properly.

Table 5 shows the association between respondent's food handling practices and demographic characteristics.
The logistic regression analysis revealed that the odds of performing good handling practice among respondents within the age group of 36-45 years were five times higher compared to those within the age group of $18-25$ years [OR $=4.92(95 \%$ CI: $1.44-16.86), p=0.011]$. Moreover, respondents who had tertiary education qualification were more likely to have proper food handling practices compared to those with primary education [OR $=0.27$ (95\% CI: 0.09-0.71), $p=0.009$ ]. Respondents who had three children were thrice more likely to have proper food handling practices [OR $=2.86$ (95\% CI: 1.09-7.49), $p=0.033$ ] compared with those who had one child.

Table 6 shows the association between respondent's food preparation practices and demographic characteristics. The logistic regression analysis revealed that mothers whose monthly income were GHC 600-1000 were two times more likely to have good hygienic food preparation practices compared to those with less than GHC 500 as monthly income [OR $=2.45$ (95\% CI: $1.44-4.17), p=0.001$ ].

Table 7 shows the association between respondent's food storage practices and demographic characteristics. The logistic regression analysis indicates that respondents who were not married were less likely to have good food storage practices compared to those who were married [OR $=0.06(95 \%$ CI: $0.02-0.21), p<0.001]$. Also, mothers who had secondary and tertiary education were less likely to have good food 
TABLE 4: Food storage practices among the respondents.

\begin{tabular}{lcc}
\hline Variable & Frequency & Percentage \\
\hline Purchase frozen/refrigerated food when shopping & & 96.3 \\
At the end of the shopping trip & 289 & 1.3 \\
At the beginning of the shopping trip & 4 & 2.4 \\
Whenever, does not matter & 7 & 95.00 \\
Prepared food that will be consumed 3-4 hours later & 285 & 2.3 \\
Put it on the table/counter, then reheat before consumption & 7 & 2.7 \\
Put it in the refrigerator, then reheat before consumption & 8 & 91.0 \\
Store it in the microwave oven or regular oven, then reheat before consumption & & 8.0 \\
Eggs can contain germs. How to store raw eggs at home & 273 & 1.0 \\
Wash them with soap and water and store in the refrigerator & 24 & 87.7 \\
Wipe with a dry cloth and store in the refrigerator & 3 & 9.6 \\
Store directly in the refrigerator then wash your hands after touching them & & 2.7 \\
Leftovers should be kept in the fridge & 263 & 29 \\
No more than 2 days & 8 & 88.3 \\
No more than 5 days & & 5.3 \\
As long as they smell good, we can eat them & 265 & 5.0 \\
Most dangerous way to thaw frozen meat & 16 & 1.4 \\
Thaw in the refrigerator & 15 & 91.3 \\
Thaw on the kitchen counter & 4 & 1.7 \\
Use the microwave oven and then cook immediately & & 7.0 \\
Thaw under cold water & 274 & 5 \\
Reheated leftovers (in microwave) still not eaten completely & 21 & \\
Discard them immediately & &
\end{tabular}

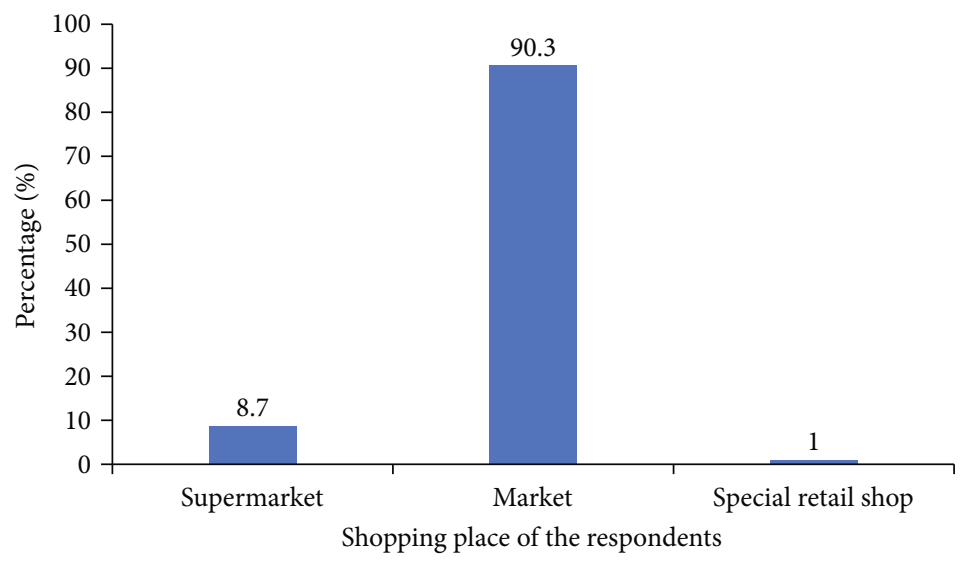

FigURE 2: Shopping place of the respondents.

storage practices compared to those with primary education $[\mathrm{OR}=0.01$ (95\% CI:0.003-0.05), $p<0.001]$ and $[\mathrm{OR}=0.05$ (95\% CI:0.02-0.17), $p<0.001]$, respectively; however, the odds of having good food preparation practice among mothers who had three children were elevenfold higher as compared to those with one child $[\mathrm{OR}=10.98$ (95\% CI: $3.25-37.13), p<0.001]$.
3.2. Discussion. The present study investigated food safety practices and its associated factors among postnatal mothers in the Western Region of Ghana. Findings of this study will help to inform policy decisions that will aid improving food safety practices of postnatal mothers in this region.

Food safety practices of the participants were investigated in three categories including food handling practices, food 


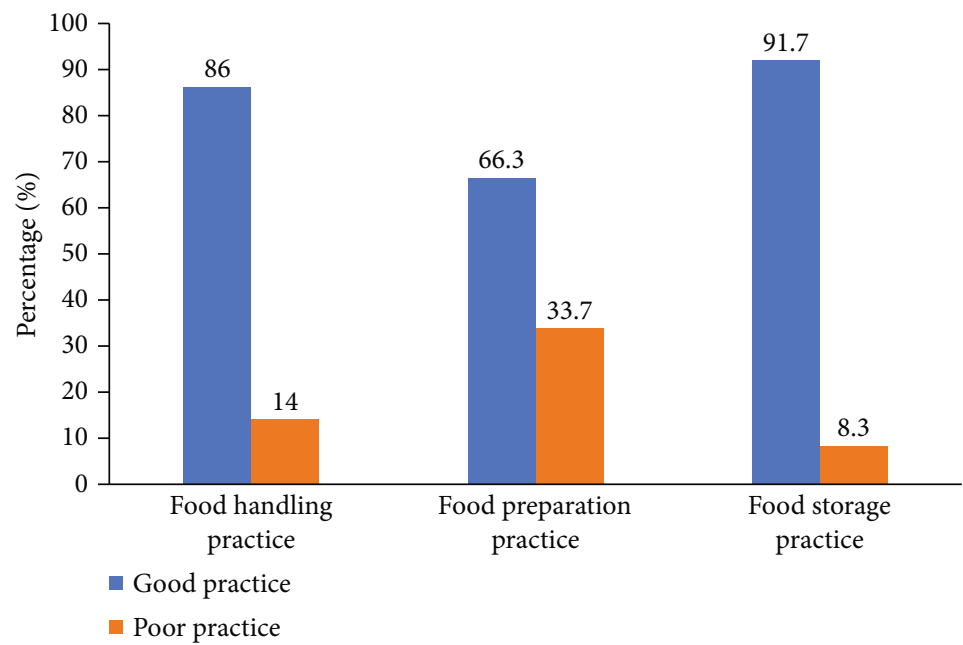

FIGURE 3: Food handling, preparation, and storage practices among respondents.

TABLE 5: Association between food handling practices and respondent's demographic characteristics.

\begin{tabular}{|c|c|c|c|c|c|}
\hline \multirow[b]{2}{*}{ Variable } & \multicolumn{2}{|c|}{ Food handling practices } & \multirow[b]{2}{*}{$\chi^{2}$} & \multirow[b]{2}{*}{$p$ value } & \multirow[b]{2}{*}{ OR (95\% CI), $p$ value } \\
\hline & $\begin{array}{c}\text { Poor practice }=42 \\
n(\%)\end{array}$ & $\begin{array}{c}\text { Proper practice }=258 \\
n(\%)\end{array}$ & & & \\
\hline Age group & & & 8.69 & 0.034 & \\
\hline $18-25$ years & $10(23.8)$ & $34(13.2)$ & & & \\
\hline 26-35 years & $28(66.7)$ & $149(57.8)$ & & & 1.57 (0.69-3.53), 0.280 \\
\hline $36-45$ years & $4(9.5)$ & $67(25.9)$ & & & 4.93 (1.44-16.87), 0.011 \\
\hline Above 45 years & $0(0.0)$ & $8(3.1)$ & & & 1 (empty) \\
\hline Monthly income & & & 6.90 & 0.075 & \\
\hline$<$ Ghc500 & $15(35.8)$ & $68(26.4)$ & & & \\
\hline Ghc600-1000 & $21(50.0)$ & $175(67.8)$ & & & $1.84(0.89-3.77), 0.097$ \\
\hline Ghc1001-1500 & $3(7.1)$ & $9(3.5)$ & & & $0.66(0.16-2.74), 0.569$ \\
\hline$>$ Ghc1500 & $3(7.1)$ & $6(2.3)$ & & & $0.44(0.09-1.93), 0.283$ \\
\hline Marital status & & & 1.82 & 0.402 & \\
\hline Married & $39(92.9)$ & $249(96.5)$ & & & \\
\hline Single & $3(7.1)$ & $8(3.1)$ & & & $0.42(0.10-1.64), 0.211$ \\
\hline Divorced & $0(0.0)$ & $1(0.4)$ & & & 1 (empty) \\
\hline Type of delivery & & & 2.19 & 0.138 & \\
\hline Normal & $39(92.9)$ & $251(97.3)$ & & & \\
\hline Caesarean & $3(7.1)$ & $7(2.7)$ & & & $0.36(0.09-1.46), 0.154$ \\
\hline Educational level & & & 7.85 & 0.020 & \\
\hline Primary & $33(78.6)$ & $231(89.5)$ & & & \\
\hline Secondary & $2(4.8)$ & $14(5.4)$ & & & $1.00(0.22-4.59), 1.000$ \\
\hline Tertiary & $7(16.7)$ & $13(5.1)$ & & & $0.27(0.09-0.71), 0.009$ \\
\hline Number of children & & & 28.92 & $<0.001$ & \\
\hline One & $7(16.7)$ & $26(10.1)$ & & & \\
\hline Two & $15(35.7)$ & $37(14.3)$ & & & $0.66(0.24-1.86), 0.435$ \\
\hline Three & $18(42.8)$ & $191(74.0)$ & & & 2.86 (1.09-7.49), 0.033 \\
\hline Four & $0(0.0)$ & $4(1.6)$ & & & 1 (empty) \\
\hline Five & $2(4.8)$ & $0(0.0)$ & & & 1 (empty) \\
\hline
\end{tabular}

preparation/personal hygiene practices, and food storage practices. The postnatal mothers demonstrated good selfreported knowledge on food handling and food storage prac- tices with a passing rate of $86 \%$ and $91.7 \%$, respectively. However, the postnatal mothers had relatively, moderate self-reported knowledge on safe food preparation/personal 
TABle 6: Association between food preparation practices and respondent's demographic characteristics.

\begin{tabular}{|c|c|c|c|c|c|}
\hline \multirow{2}{*}{ Variable } & \multicolumn{2}{|c|}{ Food preparation practices } & \multirow{2}{*}{$\chi^{2}$} & \multirow{2}{*}{$p$ value } & \multirow{2}{*}{ OR (95\% CI), $p$ value } \\
\hline & Unhygienic $=101, n(\%)$ & Hygienic $=199, n(\%)$ & & & \\
\hline Age group & & & 5.38 & 0.146 & \\
\hline $18-25$ years & $14(13.9)$ & $30(15.1)$ & & & \\
\hline 26-35 years & $55(54.5)$ & $122(61.3)$ & & & $1.04(0.51-2.11), 0.924$ \\
\hline $36-45$ years & $31(30.7)$ & $40(20.1)$ & & & $0.60(0.27-1.33), 0.208$ \\
\hline Above 45 years & $1(0.9)$ & $7(3.5)$ & & & 3.27 (0.37-29.17), 0.289 \\
\hline Monthly income & & & 11.13 & 0.011 & \\
\hline$<$ Ghc500 & $40(39.6)$ & $43(21.6)$ & & & \\
\hline Ghc600-1000 & $54(53.4)$ & $142(71.4)$ & & & 2.45 (1.44-4.17), 0.001 \\
\hline Ghc1001-1500 & $4(4.0)$ & $8(4.0)$ & & & $1.86(0.52-6.66), 0.340$ \\
\hline$>$ Ghc1500 & $3(3.0)$ & $6(3.0)$ & & & $1.86(0.44-7.94), 0.402$ \\
\hline Marital status & & & 0.54 & 0.762 & \\
\hline Married & $97(96.0)$ & $191(96.0)$ & & & \\
\hline Single & $4(4.0)$ & $7(3.5)$ & & & $0.89(0.25-3.11), 0.854$ \\
\hline Divorced & $0(0.0)$ & $1(0.5)$ & & & 1 (empty) \\
\hline Type of delivery & & & 0.19 & 0.666 & \\
\hline Normal & $97(96.0)$ & $193(97.0)$ & & & \\
\hline Caesarean & $4(4.0)$ & $6(3.0)$ & & & $0.75(0.21-2.73), 0.667$ \\
\hline Educational level & & & 2.74 & 0.254 & \\
\hline Primary & $89(88.1)$ & $175(88.0)$ & & & \\
\hline Secondary & $3(3.0)$ & $13(6.5)$ & & & $2.20(0.61-7.93), 0.227$ \\
\hline Tertiary & $9(8.9)$ & $11(5.5)$ & & & $0.62(0.25-1.56), 0.310$ \\
\hline Number of children & & & 14.69 & 0.005 & \\
\hline One & $14(13.9)$ & $19(9.5)$ & & & \\
\hline Two & $26(25.7)$ & $26(13.1)$ & & & $0.74(0.31-1.77), 0.496$ \\
\hline Three & $58(57.4)$ & $151(75.9)$ & & & $1.92(0.90-4.08), 0.90$ \\
\hline Four & $1(1.0)$ & $3(1.5)$ & & & $2.21(0.21-23.56), 0.511$ \\
\hline Five & $2(2.0)$ & $0(0.0)$ & & & 1 (empty) \\
\hline
\end{tabular}

hygiene practices with a passing rate of $66.3 \%$. These results are higher compared to studies among mothers in the Northeast Ethiopia [1], Saudi Arabia [12], and Miami, Florida (Trepka, 2007), as well as studies among food vendors in Nigeria [18, 19] and Ghana [20].

Though generally, respondents had good self-reported knowledge on food safety practice scores, and there were certain specific noteworthy findings. First of all, regarding food handling practices, $82.7 \%$ of the postnatal mothers disagreed "it is not necessary to handle food during infectious disease of the skin." It signified that this these mothers either do not see anything wrong with handling food when the handler has a skin infection or have not been exposed to education on the possible crosscontamination that could occur in such a scenario. One of the ways to avoid foodborne bacteria illnesses or diseases is to prevent individuals with skin disease or lesions from handling food $[21,22]$. Thus, there is a gap in the knowledge of the postnatal mothers in the SekondiTakoradi Metropolis in this regard.

Furthermore, most of the respondents were of the notion that it was not always necessary to keep finger nails short and clean during food preparation as $80.4 \%$ of the postnatal mothers indicated that this can be done sometimes. How- ever, the World Health Organization [23] emphasizes the need for food handlers to always keep their nails short and clean. It is still dangerous to manipulate foodstuffs during food preparation even with long but clean nails because Rane [24] revealed that pathogens such as Salmonella, nontyphi salmonellae, Campylobacter, and E. coli can inhabit fingertips for varied periods of time. Thus, it is necessary for food handlers and food vendors to keep their finger nails short and clean to prevent them from being transmitting agents of pathogens [25].

In Ghana, there are three places to shop for food items, food ingredients, or ready to eat meals, and these are supermarkets, traditional markets, and special retail shops. A large majority of the postnatal mothers revealed the traditional markets as their shopping destinations as opposed to the supermarket and special retail shops. There are several likely explanations to this observation. Firstly, the traditional food retail outlet remains significant in Ghana's agri-food system $[26,27]$. Meng et al., (2014), revealed through their findings that these traditional open-air markets still dominate the Ghana food retailing system. Moreover, such markets provide large households with locally produced foods at a cost that favours individuals with low incomes and low 
TABLE 7: Association between food storage practices and respondent's demographic characteristics.

\begin{tabular}{|c|c|c|c|c|c|}
\hline \multirow{2}{*}{ Variable } & \multicolumn{2}{|c|}{ Food storage practices } & \multirow{2}{*}{$\chi^{2}$} & \multirow{2}{*}{$p$ value } & \multirow{2}{*}{ OR (95\% CI), $p$ value } \\
\hline & Poor storage $=25, n(\%)$ & Good storage $=275, n(\%)$ & & & \\
\hline Age group & & & 4.87 & 0.182 & \\
\hline $18-25$ years & $5(20.0)$ & $39(14.2)$ & & & \\
\hline $26-35$ years & $18(72.0)$ & $159(57.8)$ & & & $1.13(0.39-3.24), 0.817$ \\
\hline $36-45$ years & $2(8.0)$ & $69(25.1)$ & & & $4.42(0.82-23.88), 0.084$ \\
\hline Above 45 years & $0(0.0)$ & $8(2.9)$ & & & 1 (empty) \\
\hline Monthly income & & & 1.62 & 0.655 & \\
\hline$<$ Ghc500 & $9(36.0)$ & $74(26.9)$ & & & \\
\hline Ghc600-1000 & $15(60.0)$ & $181(65.8)$ & & & $1.47(0.62-3.50), 0.387$ \\
\hline Ghc1001-1500 & $1(4.0)$ & $11(4.0)$ & & & $1.34(0.15-11.61), 0.792$ \\
\hline$>$ Ghc1500 & $0(0.0)$ & $9(3.3)$ & & & 1 (empty) \\
\hline Marital status & & & 31.98 & $<0.001$ & \\
\hline Married & $19(76.0)$ & $269(97.8)$ & & & \\
\hline Single & $6(24.0)$ & $5(1.8)$ & & & $0.06(0.02-0.21),<0.001$ \\
\hline Divorced & $0(0.0)$ & $1(0.4)$ & & & 1 (empty) \\
\hline Type of delivery & & & 36.15 & $<0.001$ & \\
\hline Normal & $19(76.0)$ & $271(98.6)$ & & & \\
\hline Caesarean & $6(24.0)$ & $4(1.4)$ & & & $0.05(0.01-0.18),<0.001$ \\
\hline Educational level & & & 106.23 & $<0.001$ & \\
\hline Primary & $7(28.0)$ & $257(93.5)$ & & & \\
\hline Secondary & $11(44.0)$ & $5(1.8)$ & & & $0.01(0.003-0.05),<0.001$ \\
\hline Tertiary & $7(28.0)$ & $13(4.7)$ & & & $0.05(0.02-0.17),<0.001$ \\
\hline Number of children & & & 50.12 & $<0.001$ & \\
\hline One & $7(28.0)$ & $26(9.4)$ & & & \\
\hline Two & $9(36.0)$ & $43(15.6)$ & & & $1.29(0.43-3.87), 0.654$ \\
\hline Three & $5(20.0)$ & $204(74.2)$ & & & $10.98(3.25-37.13),<0.001$ \\
\hline Four & $3(12.0)$ & $1(0.4)$ & & & 0.09 (0.01-1.00), 0.050 \\
\hline Five & $1(4.0)$ & $1(0.4)$ & & & $0.27(0.01-4.87), 0.374$ \\
\hline
\end{tabular}

educational background [27]. These corroborate with the income and educational profile of most respondents in the present study. It is worth noting that other factors such as easy availability and accessibility to the traditional markets as compared to the other markets could be possible reasons as well.

Bivariate multilogistic analysis revealed associated factors linked to food handling practices, food preparation practices, and food storage practices among the respondents. There was no significant association between level of food handling practices and respondents' age group, monthly income, marital status, occupational status, type of delivery, and educational level. This was consistent with a similar study by Aung et al. [28], where there was no significant association between the age group, income level, educational level, and food handling practice of the respondents. However, in the present study, there was an association between food handling practice and respondents' religion, ethnicity, place of residence, occupational status, and number of children. Regarding of food preparation practices, there were only significant associations between ethnicity and number of children. For food storage practices, findings revealed marital status, religion, place of residence, occupational status, type of delivery, educational level, and number of children as significant associating factors.

The above findings revealed few inconsistencies in associated factors of food handling, preparation, and storage practices among the postnatal mothers in the Western Region of Ghana. For instance, the educational level was a significant associated factor of food storage practices among the respondents but was insignificant with regards to their food handling and food preparation practices. Regardless, it would still be less productive for appropriate stakeholders and policymakers to increase the literacy rate of the postnatal mothers in an attempt to improve their food storage practices. This is because results showed that respondents with primary education were more likely to have hygienic food storage practices as compared to those with secondary and tertiary educational background. In contrast, other studies reported that higher educational background of the respondents was associated with good food safety practices $[1,12,29,30]$. The number of children among the respondents was the only consistent associated factor across the three categories of food safety practices. In summary, 
associated factors of food safety practices among the postnatal mothers in the Western Region of Ghana require further investigations to fully understand or explain.

\section{Conclusion}

The self-reported food safety practices among the respondents were generally good. However, the respondents indicated higher knowledge in hygienic food handling and food storage practices as compared to food preparation practices. Specifically, most respondents did not agree on keeping short and clean nails always when preparing food and also not handling food when the handler has a skin infection or lesion. Thus, there should policies that should be made towards enlightening postnatal mothers in the Western Region of Ghana in this regard. The present study found out significant associated factors of food safety practices among the respondents. However, the inconsistencies in the findings require further investigations to clearly understand and explain.

\section{Data Availability}

The data used to support the findings of this study are included within the article.

\section{Conflicts of Interest}

The authors declare no conflicts of interest.

\section{Authors' Contributions}

ST Odonkor and N Kurnatin designed the study, collected the test data, and interpreted the results. ST Odonkor and AM Sallar drafted the manuscript. All authors reviewed the manuscript.

\section{References}

[1] H. Dagne, R. P. Raju, Z. Andualem, T. Hagos, and K. Addis, "Food safety practice and its associated factors among mothers in Debarq town, Northwest Ethiopia: community-based crosssectional study," BioMed Research International, vol. 2019, Article ID 1549131, 8 pages, 2019.

[2] K. Kraemer, J. Cordaro, J. Fanzo et al., Chapter 5.7 The critical role of food safety in ensuring food security in good nutrition: perspectives for the 21st century, Karger publishers, 2016.

[3] A. H. Havelaar, M. D. Kirk, P. R. Torgerson et al., "World health organization global estimates and regional comparisons of the burden of foodborne disease in 2010," PLoS Medicine, vol. 12, no. 12, article e1001923, 2015.

[4] A. J. Linscott, "Food-borne illnesses," Clinical Microbiology Newsletter, vol. 33, no. 6, pp. 41-45, 2011.

[5] B. Osei-Tutu and F. Anto, "Trends of reported foodborne diseases at the ridge hospital, Accra, Ghana: a retrospective review of routine data from 2009-2013," BMC Infectious Diseases, vol. 16, no. 1, p. 139, 2016.

[6] P. Dudeja, A. Singh, N. Sahni, S. Kaur, and S. Goel, "Effectiveness of an intervention package on knowledge, attitude, and practices of food handlers in a tertiary care hospital of North India: a before and after comparison study," Medical Journal, Armed Forces India, vol. 73, no. 1, pp. 49-53, 2017.
[7] D. Grace, "Food safety in low and middle income countries," International Journal of Environmental Research and Public Health, vol. 12, no. 9, pp. 10490-10507, 2015.

[8] A. Mudey, N. Kesharwani, G. Mudey, R. Goyal, A. Dawale, and V. Wagh, "Health status and personal hygiene among food handlers working at food establishment around a rural teaching hospital in Wardha District of Maharashtra, India," Global Journal of Health Science, vol. 2, no. 2, p. 198, 2010.

[9] M. J. Trepka, F. L. Newman, Z. Dixon, and F. G. Huffman, "Food safety practices among pregnant women and mothers in the women, infants, and children program, Miami, Florida," Journal of Food Protection, vol. 70, no. 5, pp. 1230-1237, 2007.

[10] M. Fawzi and M. E. Shama, "Food safety knowledge and practices among women working in Alexandria University, Egypt," The Journal of the Egyptian Public Health Association, vol. 84, no. 1-2, pp. 95-117, 2009.

[11] M. Jevšnik, V. Hlebec, and P. Raspor, "Consumers' awareness of food safety from shopping to eating," Food Control, vol. 19, no. 8, pp. 737-745, 2008.

[12] W. O. Ayaz, A. Priyadarshini, and A. K. Jaiswal, "Food safety knowledge and practices among Saudi mothers," Food, vol. 7, no. 12, p. 193, 2018.

[13] F. Akabanda, E. H. Hlortsi, and J. Owusu-Kwarteng, "Food safety knowledge, attitudes and practices of institutional food-handlers in Ghana," BMC Public Health, vol. 17, no. 1, p. 40, 2017.

[14] A. P. Kunadu, D. B. Ofosu, E. F. Aboagye, and K. TanoDebrah, "Food safety knowledge, attitudes and self-reported practices of food handlers in institutional foodservice in Accra, Ghana," Food Control, vol. 69, pp. 324-330, 2016.

[15] N. A. Manko, Hygienic Practices of Food Vendors: Effect on Consumer Food Safety on the University of Ghana Campus, [Ph.D. thesis], University of Ghana, 2018, http://ugspace.ug .edu.gh/handle/123456789/26169.

[16] L. Sharif and T. Al-Malki, "Knowledge, attitude and practice of Taif University students on food poisoning," Food Control, vol. 21, no. 1, pp. 55-60, 2010.

[17] R. L. Miller and J. D. Brewer, Eds., The AZ of Social Research: A Dictionary of Key Social Science Research Concepts, Sage, 2003.

[18] T. Afolaranmi, Z. Hassan, Z. Misari et al., "Food safety and hygiene practices among food vendorsin tertiary hospitals Inplateau state Nigeria," Journal of Medical Research, vol. 4, no. 2, pp. 16-22, 2017.

[19] F. A. Faremi, M. I. Olatubi, and G. Nnabuife, "Food safety and hygiene practices among food vendors in a tertiary educational institution in South Western Nigeria," European Journal of Nutrition \& Food Safety, vol. 8, no. 2, pp. 59-70, 2018.

[20] A. Larbi, Food Hygiene and Safety among Food Vendors in Ghana, Grin Verlag, 2019.

[21] M. Addis and D. Sisay, "A review on major food borne bacterial illnesses," Journal of Tropical Diseases \& Public Health, vol. 3, no. 4, pp. 176-183, 2015.

[22] World Health Organization, Foodborne Disease Outbreaks: Guidelines for Investigation and Control, World Health Organization, 2008, https://apps.who.int/iris/handle/10665/43771.

[23] World Health Organization, WHO Estimates of the Global Burden of Foodborne Diseases: Foodborne Diseases Burden Epidemiology Reference Group 2007-2015, World Health Organization, 2015. 
[24] S. Rane, "Street vended food in developing world: hazard analyses," Indian Journal of Microbiology, vol. 51, no. 1, pp. 100106, 2011.

[25] J. F. Lues, M. R. Rasephei, P. Venter, and M. M. Theron, "Assessing food safety and associated food handling practices in street food vending," International Journal of Environmental Health Research, vol. 16, no. 5, pp. 319-328, 2006.

[26] S. Field, O. Masakure, and S. Henson, "Rethinking localization-a low-income country perspective: the case of Asian vegetables in Ghana," Cambridge Journal of Regions, Economy and Society, vol. 3, no. 2, pp. 261-277, 2010.

[27] T. Meng, W. J. Florkowski, D. B. Sarpong, M. S. Chinnan, and A. V. Resurreccion, "Consumer's food shopping choice in Ghana: supermarket or traditional outlets?," International food and agribusiness management review, vol. 17, pp. 107130, 2014.

[28] S. Aung, A. Nwe, W. Shan, S. Naing, S. Htay, and K. Kyaw, "Food handling practices among food handlers of eating establishments in the government hospitals, Mandalay City, Myanmar," Archives of Current Research International, vol. 16, no. 2, pp. 1-14, 2019.

[29] R. V. Sudhersan, G. S. Rago, P. Rao, M. V. V. Rao, and K. Polasa, "Food safety related perceptions and practices of mothers - a case study in Hyderabad, India," Food Control, vol. 19, no. 5, pp. 506-513, 2008.

[30] G. M. Subba Rao, R. V. Sudershan, P. Rao, M. Vishnu Vardhana Rao, and K. Polasa, "Food safety knowledge, attitudes and practices of mothers: findings from focus group studies in South India," Appetite, vol. 49, no. 2, pp. 441-449, 2007. 